\title{
A PROBLEMÁTICA DA ECONOMIA SOLIDÁRIA: UMA PERSPECTIVA INTERNACIONAL
}

\author{
Genauto Carvalho de França Filho
}

Resumo. O presente artigo apresenta e discute a temática da economia solidária. Trata da sua origem, como conceito e do seu contexto de emergência, como fenômeno, situando-a numa problemática européia que lhe é fundadora. O texto procura também interpretar o sentido de tal tipo de prática apoiando-se em pressupostos de uma tradição de estudos do campo da Antropologia econômica. Esta abordagem demonstra grande pertinência ao sugerir uma desconstrução da idéia convencional de Economia, o que permite a apreensão de certas dimensões do fenômeno que apareceriam despercebidas numa visão econômica neoclássica. $\mathrm{O}$ texto oferece ainda uma leitura acerca das diferentes formas de manifestação da economia solidária no contexto europeu de realidade, buscando sublinhar alguns dos principais dilemas e desafios enfrentados na prática quotidiana de tais experiências, e conclui com uma reflexão sobre o caso brasileiro de manifestação do fenômeno. Trata-se de um texto ao mesmo tempo descritivo e analítico, com um leve tom ensaístico, sugerindo uma reflexão crítica de âmbito internacional sobre os limites e possibilidades do tema.

Palavras-chave: Economia solidária, associativismo, economia plural, novas formas de solidariedade.

\section{Introdução}

A temática da economia solidária tem despertado o interesse crescente da comunidade acadêmica nos últimos anos. Publicações a

Genauto Carvalho de França Filho é doutor em Sociologia; mestre e graduado em Administração; professor da Escola de Administração da UFBA e do seu Proprama de Pós-Graduação (NPGA); pesquisador do Núcleo de Estudos sobre Poder e Organizações Locais (NEPOL). 
respeito já começam a aparecer em diferentes campos disciplinares, como Economia, Sociologia ou Administração. Um tal interesse acadêmico parece fazer eco àquele que se verifica na realidade através da iniciativa de diferentes atores associativos, representantes dos poderes públicos e mesmo entidades sindicais, o que leva o tema a ocupar lugar de destaque em certos eventos, como foi o caso do recente Fórum Social Mundial, realizado em Porto Alegre.

Alternativa real à crescente crise do emprego verificada em diferentes sociedades ou mero paliativo à crise de ajustamento de um sistema capitalista que se renova, diferentes são os diagnósticos acerca do alcance e limites do tema. Diferenças nesta leitura à parte, um fato merece destaque: tal fenômeno ganha relevância neste novo cenário atual de reconfiguração das relações entre Estado e mercado, em que desponta com força a idéia de um terceiro setor. Terceiro setor e economia solidária, embora pareçam termos correlatos, pertencem a universos semânticos distintos, apontando para não somente diferentes contextos sociopolíticos de emergência de cada termo, mas, também, a interpretações diferentes sobre o papel desempenhado (ou a desempenhar) por estas experiências e, em particular, no que se refere à posição que elas devem ocupar em relação às esferas do Estado e do mercado (França, 2002).

Iremos a seguir, num primeiro momento, apresentar essa temática sublinhando, em particular, sua origem enquanto conceito, seu contexto de emergência enquanto fenômeno e o tipo de problemática que ela suscita. Para concluir esta parte, discutiremos um modo específico de interpretação desse fenômeno a partir de uma perspectiva de Antropologia econômica, que consideramos fecunda para a apreensão da sua natureza específica. Num segundo momento, abordaremos algumas implicações práticas desse fenômeno, propondo uma tipologia sobre suas formas de manifestação no contexto europeu mais geral e francês em particular. O objetivo aqui é de sublinhar alguns limites e desafios enfrentados na prática concreta dessas iniciativas. À guisa de conclusão, relacionaremos tal debate ao contexto brasileiro num sentido de esboçar os primeiros elementos de uma comparação internacional do fenômeno. 


\section{As origens de um conceito - alguns marcos teóricos de sua fundação}

Enquanto noção ou conceito, o termo economia solidária identifica uma série de experiências organizacionais inscritas numa dinâmica atual em torno das chamadas novas formas de solidariedade. Estas novas formas de solidariedade fazem alusão à iniciativa cidadã em oposição, ao mesmo tempo, às formas abstratas de solidariedade praticadas historicamente pelo Estado, de um lado, e às formas tradicionais de solidariedade marcadas pelo caráter comunitário. Neste sentido, estamos diante de um fenômeno efetivamente inédito, segundo nossa hipótese, pois estas experiências não parecem orientar-se segundo o registro de uma socialidade típica da Gemeinschaft (comunidade), princípio comunitário (Tönnies), ou seja, uma socialidade comunitária (Weber), ou ainda, uma solidariedade mecânica característica das sociedades tradicionais (Durkheim). De fato, se um tipo de dinâmica comunitária marca estas experiências, sua expressão não parece identificar-se ao registro de um comunitarismo herdado (conforme nos lembram Caillé e Laville), "na medida em que ela emana de um comunitarismo muito mais escolhido como referência coletiva a um bem comum do que imposto pelo costume". ${ }^{1}$ Além disso, o caráter inédito destas novas formas de solidariedade reside ainda na afirmação de uma tal dinâmica comunitária no seio de uma sociedade em que as relações relevam primeiro de uma solidariedade orgânica (Durkheim) ou da Gesellschaft (sociedade), princípio societário (Tönnies), ou ainda da socialidade societária (Weber).

Portanto, experiências associativas em geral, marcadas por uma dinâmica comunitária do ponto de vista interno, mas ao mesmo tempo abertas sobre o espaço público, estes traços parecem constituir uma primeira característica central que vem marcar o fenômeno da economia solidária, que inclusive, vale ressaltar, circunscreve um universo específico de experiências neste domínio das novas formas de solidariedade. Embora devamos reconhecer a especificidade dos diferentes contextos societários (França, 2002), importa salientar um certo grau de universalidade na manifestação deste fenômeno. Isto é, as novas formas de solidariedade dizem respeito a uma série de iniciativas de organizações de caráter social que ganha força neste contexto de crise dos mecanismos de regulação da sociedade, em especial na crise 
do Estado-Providência. Um traço forte de tal fenômeno é sua diversidade: algumas iniciativas procurando afirmar mais o seu caráter político, outras apenas remodelando uma prática assistencial, num universo onde tem lugar desde a filantropia até a cooperação, passando pela ajuda mútua e pela reciprocidade, como diferentes manifestações da solidariedade. Assim, embora não tenhamos a mesma tradição de Estado social em relação àquela da Europa, parece inegável reconhecer, mesmo no nosso contexto latino-americano, a profusão recente de diferentes práticas de solidariedade que vêm acrescentar-se às formas já conhecidas de organização do meio social, traduzidas na noção de economia popular (ver França, 2002). O que confirma o caráter relativamente universal dessas novas formas de solidariedade.

Mas se a idéia de economia solidária aparece no bojo dessas chamadas novas formas de solidariedade, parece-nos instrutivo neste momento indagar sobre como se elaborou especificamente tal conceito. De modo preciso, o termo economia solidária fora forjado no início dos anos 90, através dos trabalhos de Jean Louis Laville e Bernard Eme, na França. Através deste termo, estes autores visavam a dar conta da emergência e desenvolvimento de um fenômeno de proliferação de iniciativas e práticas socioeconômicas diversas. São as chamadas iniciativas locais na Europa. Elas assumem, na maioria dos casos, a forma associativa e buscam responder a certas problemáticas locais específicas. Esta expressão, economia solidária, vem, assim, num primeiro momento, indicar, por um lado, a associação de duas noções historicamente dissociadas, isto é, iniciativa e solidariedade; e, por outro lado, sugere-se (com estas experiências) a inscrição da solidariedade no centro mesmo da elaboração coletiva de atividades econômicas.

Busca-se, portanto, (através desta noção de economia solidária) uma tentativa de problematização dessas novas práticas organizativas a partir de um quadro de referências bem preciso: ou seja, aquele de uma reflexão sobre as relações entre democracia e economia, que se inspira amplamente nos trabalhos de Karl Polanyi. ${ }^{2}$ Abre-se, assim, através dessa noção, uma perspectiva descritiva e compreensivista de pesquisa, reenviando à análise de realizações existentes que, em diferentes partes do mundo, representam hoje milhares de experiências e dezenas de milhares de assalariados e de voluntários implicados (Eme e Laville, 1996). 


\section{Contexto e delineamento de um fenômeno}

Trata-se, portanto, de um conceito elaborado num contexto europeu de formulação e discutiremos mais tarde seu sentido aplicado ao caso brasileiro. Enquanto fenômeno, a emergência de uma economia solidária está intimamente ligada à problemática de uma exclusão social crescente, que se define cada vez mais enquanto questão urbana, num contexto atual (isto é, que remonta já a mais de vinte anos) de crise do Estado-Providência. ${ }^{3}$ A realidade de uma economia solidária e sua problemática vêm, assim, se posicionar num contexto de falência dos mecanismos de regulação econômico-políticos da sociedade. Estes foram fundados historicamente em torno de duas esferas principais de organização das relações político-econômico-sociais - o Estado e o mercado, encontrando no trabalho, no sentido moderno do termo, ou seja, na relação assalariada, sua estruturação fundamental. ${ }^{4} \mathrm{O}$ fenômeno da economia solidária se apresenta, assim, segundo esse entendimento, numa perspectiva de busca de novas formas de regulação da sociedade - mesmo que de modo ainda extremamente modesto no momento presente.

Buscando precisar a definição, sublinhamos que a emergência de uma economia solidária (ou sua noção) traduz-se por uma florescência de práticas socioeconômicas na Europa visando a propor (a partir de iniciativas locais) serviços de um tipo novo, designados sob o termo "serviços de proximidade" ou "serviços solidários". Esse termo faz alusão a um conjunto de serviços, para alguns outrora unicamente produzidos no seio da esfera doméstica, como ajuda a domicílio, jardinagem, consertos domésticos (bricolage) etc., e para outros, invenção, como é o caso dos serviços que giram em torno da questão da «mediação social» nos bairros, geralmente vinculados à idéia de melhoria da qualidade de vida e do meio ambiente local (Laville, 1992). Foram justamente através dos trabalho de descrição destas práticas/ experiências, articulados à elaboração de um modo de compreendê-las, visando a apreensão da sua singularidade enquanto fenômeno, que a noção de economia solidária fora forjada por Laville e Eme.

Assistimos, assim, ao nascimento de iniciativas locais portadoras de um caráter novo, relativo, ao mesmo tempo, ao seu modo de funcionamento e à sua finalidade. Pois estas experiências reúnem 
usuários, profissionais e voluntários, preocupados em articular criação de emprego e reforço da coesão social, ou geração de atividades econômicas, com fins de produção do chamado liame social (ou dos laços sociais), ou, simplesmente, geração de atividades econômicas, com finalidades sociais.

\section{Situando uma problemática}

Dois traços característicos maiores resumem a especificidade dos serviços de proximidade (ou solidários) e posicionam a hipótese da economia solidária enquanto modo de regulação:

a) Hibridação de economias (ou de recursos) - A fim de permitir a perenidade dos projetos criados, pois articulam-se aqui distintas fontes de recursos. Estas são de natureza:

- não mercantil: através de subvenções ou outros financiamentos à atividade oriundos do poder público (qualquer que seja a instância de governo) - recurso ao Estado;

- mercantil: através de venda ou prestação de serviços a particulares (pessoa física ou jurídica) - recurso ao mercado;

- não monetária: através da participação voluntária de certos membros, ou seja, a doação sob a forma material ou humana (doação de tempo, etc.) - recurso a uma lógica reciprocitária ou uma lógica da dádiva;

b) Construção conjunta da oferta e da demanda - Isto é, os serviços são concebidos e propostos em função de necessidades sociais reais exprimidas localmente.

Esta construção conjunta da oferta e da demanda é possível em razão da interação entre os diferentes participantes da iniciativa e os seus estatutos particulares, que podem ser múltiplos (ou difuso), isto é, ao mesmo tempo usuários e assalariados ou usuários e voluntários. ${ }^{5}$ Daí a idéia de se pensar em termos de espaço público de proximidade como 
modo de concepção destes serviços - pois debate-se sobre reais problemas enfrentados no quotidiano da realidade, favorecendo o real exercício de uma dimensão política nessas experiências (Laville, 1997).

A problemática (ou a perspectiva) da economia solidária, em termos de novas formas de regulação da sociedade (ainda que de modo modesto), pretende, assim, se opor a duas formas tradicionais de tentativa de interpretação deste fenômeno:

1) àquela que pretende enxergar estas experiências como modos de reativação de formas de socialidade comunitaristas, fortemente marcadas por um caráter de grupo fechado e balizadas pelo peso da tradição dos costumes. Segundo essa visão/leitura, as experiências de economia solidária são identificadas como uma espécie de neodomesticidade; como num retorno desesperado ao passado a fim de buscar pistas de solução para os nossos dilemas presentes. Trata-se, aqui, de uma crítica relativamente comum, partindo de certos setores à esquerda, no espectro político Europeu, que não enxergam uma dimensão política neste fenômeno;

2) àquela que apreende este fenômeno sob uma ótica liberal (à direita), ou seja, enquanto possibilidade de se constituir como setor à parte (terceiro), vindo se justapor aos dois outros (Estado e mercado), e buscando corrigir as lacunas por estes deixadas nas suas capacidades de satisfazer necessidades. Dito de outro modo, uma visão funcionalista que limita a ação da economia solidária à idéia de uma démarche funcional. Ela viria, nestes termos, preencher uma função de ajustamento social, constituindo uma espécie de economia subsidiária às formas mercantis e estatistas - papel, inclusive, que passou historicamente a exercer a economia social na França. Papel, portanto, paliativo ao sistema e que é também aquele do terceiro setor na sua versão americana de interpretação, tal como chega ao Brasil atualmente (França, 2001, 2002; Nyssens, 2000; Evers, 2000).

Ao contrário, segundo nossa interpretação, as experiências de economia solidária supõem uma articulação específica entre esferas 
econômica, social e política em razão dos diferentes registros de ação ou das diferentes lógicas que atravessam essas experiências. Trata-se, portanto, de uma forma de economia que, ao invés de se constituir como um setor à parte (terceiro), tem muito mais vocação (segundo nossa hipótese) para interagir com as formas econômicas dominantes (Estado e mercado), numa perspectiva de elaboração de arranjos particulares de princípios econômicos diversos, a fim de subordinar a lógica mercantil a outros imperativos da ação organizacional ou coletiva - por exemplo uma dinâmica reciprocitária ou um projeto associativo. Evidentemente que tal vocação não se manifesta sem dificuldades na realidade concreta dessas experiências, conforme discutiremos nas páginas que seguem.

\section{Uma perspectiva/abordagem original: a força do conceito de economia plural}

Uma tal perspectiva representa tarefa difícil nas condições da realidade atual, marcada pela hegemonia do mercado e da racionalidade que o acompanha. Nossa tomada de posição, aqui, se pretende longe de uma interpretação idealizada destas experiências, razão pela qual elas (as experiências de economia solidária) são definidas numa busca de equilíbrio, que é necessariamente frágil e muito difícil, entre as lógicas distintas que a atravessam. É exatamente esta tensão, poderíamos ainda chamar esta disputa (no sentido político forte da palavra - arendtiano), que constitui (ou que marca) intrinsecamente este fenômeno, segundo nossa leitura. Tensão, que poderíamos resumir, entre três economias (mercantil, não mercantil e não monetária), ou entre duas lógicas (instrumental e solidária ou substantiva), ou ainda, entre diferentes racionalidades da dinâmica organizacional.

Uma tal perspectiva de entendimento da economia solidária pressupõe um outro olhar em relação à economia real (seu funcionamento), não mais a reduzindo ao mercado (como faz a teoria neoclássica), mas enquanto economia plural. Ou seja, uma economia que admite uma pluralidade de princípios do comportamento econômico. Este conceito de economia plural nos permite dar conta de uma ampla dimensão da vida econômica, em especial aquela regida prioritariamente pela solidariedade, esquecida pela teoria econômica convencional, ou 
neoclássica. Esta dimensão não deve ser desprezada, pois dela depende a sobrevivência de grande parte da população no mundo. ${ }^{6}$ Pensando (ou compreendendo) dessa forma, encontramo-nos filiado à formulação polanyiana. Este autor havia já identificado quatro grandes princípios do comportamento econômico (em sua obra A grande transformação): o mercado auto-regulado, a redistribuição, a administração doméstica e a reciprocidade. Estes podem se resumir a três formas de economia com o re-arranjo destes princípios econômicos na modernidade, através da introdução de um sistema de direito jurídico-político que passa a regular as relações de trabalho - considerado meio fundamental de produção e distribuição de riquezas. Assim temos (de modo esquemático):

a) uma economia mercantil - fundada no princípio do mercado auto-regulado. Trata-se de um tipo de troca marcado pela impessoalidade e pela equivalência monetária, limitando a relação a um registro puramente utilitário, pois neste tipo de troca/relação o valor do bem (que se mede pelo seu preço) funda a lógica do sistema, ao contrário do primado do valor do laço, do liame (ou da relação social) que se busca numa lógica reciprocitária;

b) uma economia não mercantil - fundada na redistribuição. Isto é, marcada pela verticalização da relação de troca e pelo seu caráter obrigatório, pois aparece a figura de uma instância superior (o Estado) que se apropria dos recursos a fim de distribuí-los; e finalmente,

c) uma economia não monetária - fundada na reciprocidade. Isto é, um tipo de sistema de relação de trocas orientado segundo a lógica da dádiva, tal como formulada/descrita por M. Mauss. A dádiva compreende três momentos: aquele do dar, do receber e do retribuir. Neste tipo de sistema, os bens circulam de modo horizontal e o objetivo mesmo da circulação destes bens é a perenização dos laços sociais (ou a tessitura do liame social). A lógica da dádiva obedece a um tipo de determinação social específica, pois ao mesmo tempo livre e obrigada, a doação (ou esse registro de lógica) é essencialmente paradoxal. ${ }^{7}$ 
Esta apresentação de forma esquemática tem muito mais um objetivo pedag1ógico no sentido de explicitar os diferentes registros de comportamento econômico que estão em jogo dentro da chamada atividade econômica. Na prática, pois, não somente as economias de mercado não são apenas mercantis, como também sua própria prosperidade repousa sobre os pólos não mercantis - especialmente sobre todas as infra-estruturas financiadas pelos poderes públicos - e não monetário (também chamado pólo reciprocitário), isto é, sobre as relações familiares, de vizinhança, associativas etc., que contribuem de modo central com o processo de socialização dos indivíduos.

Tal tipo de argumentação permite, ainda, ultrapassar a idéia de economia de mercado como fonte única de riqueza, como também, condenar a redução das demais dimensões econômicas à condição de formas parasitárias desta última. Esta visão mais larga da economia implica, pois, enxergar estes três pólos na sua complementaridade, enquanto ao mesmo tempo, criadores e consumidores de riqueza. Nesta maneira de olhar a economia, sua redução à idéia exclusiva de mercado tornando-se insustentável, é o mito do progresso, a crença no crescimento econômico como fonte exclusiva do desenvolvimento e da felicidade que é colocada em questionamento.

Trata-se, portanto, através da referência à noção de economia plural de se pensar uma outra forma de produção e distribuição de riqueza, isto é, uma economia não necessariamente contra o mercado (imaginado-se ingenuamente ou autoritariamente que ele possa ser aniquilado), mas uma economia com mercado, entretanto sob condição que este seja submetido a outros princípios, ou melhor, que ele seja enraizado (encastré é o termo exato em francês, assim como embeddeness em inglês) junto a outros registros de práticas.

Partindo, pois, de uma definição da economia solidária como conjunto de atividades contribuindo para a democratização da economia a partir de engajamentos de cidadania (Laville, 1999), o desafio que se coloca a este fenômeno, ao nosso ver, não é, pois, aquele de um substituto da ação estatista - como numa perspectiva filantrópica, por exemplo sintomática de um processo de desregulação da economia. Mas, ao contrário, seu objetivo é muito mais aquele de uma articulação junto à esfera pública a fim de produzir uma reimbricação da economia num 
projeto de integração social e cultural. É neste sentido que consideramos que a economia solidária se apresenta como emanação de ações coletivas, buscando a instauração de novos modos de regulação, tanto no plano internacional quanto no local, a fim de completar as regulações nacionais ou suprir as suas faltas.

\section{A economia solidária do ponto de vista da sua prática quotidiana no contexto Europeu: dilemas e desafios}

Neste momento cabe destacar, de modo mais preciso, como tal abordagem se verifica em termos da realidade concreta das organizações. Com que tipo de dilemas ou desafios se defrontam tais iniciativas na sua prática quotidiana? Para cumprir tal objetivo e por razões meramente didádico-pedagógicas faremos uso do recurso tipológico. Propomos, pois, a seguir, uma tipologia de apreensão do fenômeno da economia solidária levando-se em consideração que estamos diante de um movimento multiforme de experiências. Assim, segundo nossa abordagem, em se tratando do contexto europeu mais geral e francês em particular, existem quatro formas principais de manifestação de uma economia solidária. São quatro universos de experiências, que denominamos como: o comércio justo, a finança solidária, a economia sem dinheiro e as empresas sociais. Esta tipologia se apoia fundamentalmente sobre o critério da similaridade de certas atividades. Vale relembrar que, do ponto de vista do estatuto organizacional, a forma principal de expressão destas experiências é o modo associativo (ou associativista), aparecendo ainda algumas delas sob o registro cooperativo (ou cooperativista).

\section{a) O comércio justo}

Este fenômeno participa da ambição de se construir uma solidariedade internacional, refletindo, assim, certas preocupações em torno das possibilidades de instauração de uma regulação internacional fundada sobre novas relações econômicas e comerciais. O seu objetivo é estabelecer relações comerciais mais justas entre países do Norte (consumidores em particular) e certos produtores de países do Sul. A 
esta finalidade se acrescenta uma outra, mais sob o registro de uma pedagogia política: aquela de constituição de uma rede de consumidores capaz de sensibilizar a opinião pública acerca das condições de injustiça nas regras do comércio internacional, empreendendo-se assim ações (sob a forma de campanhas, manifestações, etc.) junto a grandes instâncias institucionais de decisão em matéria política e econômica.

As organizações do comércio justo estabelecem, pois, contratos com organizações de pequenos produtores (organizados em cooperativas) para a compra e venda de produtos (em geral produtos agrícolas ou artesanais). A idéia é encontrar canais de distribuição para o escoamento daquela produção a um preço considerado justo para o pequeno produtor. Busca-se, assim, eliminar ao máximo o número de intermediários entre o produtor e o consumidor.

Herdeiro do antigo comércio alternativo, que funcionava como uma espécie de rede paralela de solidariedade para a distribuição de produtos terceiro-mundistas na Europa, o comércio justo evoluiu através de um processo de patentiamento de certos produtos, ${ }^{8}$ entre os quais, o exemplo mais conhecido, hoje, talvez seja aquele do café Max Havelaar.

O desenvolvimento deste campo do comércio justo, hoje, implica a necessidade de distinguir-se entre as experiências que limitam o seu universo de distribuição às redes das assim chamadas "boutiques associativas" ou "armazéns do mundo" - que são lojas (associativas) de venda desses produtos (como é o caso da rede Artisans du Monde na França) -; e aquelas iniciativas que se abrem sobre os grandes canais de distribuição, ou seja, as grandes cadeias de supermercados.

O processo de patentiamento de produtos, e sua conseqüente entrada no âmbito da distribuição de massa, muito influenciou o aumento das vendas dos chamados produtos équitables ou "justos", trazendo para este universo de experiências certas lógicas funcionais que passam também a interagir na dinâmica dessas formas de organização.

Observa-se, assim, que, entre dimensão socioeconômica e dimensão política, a prioridade do comércio justo implica tanto atividades de trocas comerciais (mais ou menos abertas sobre a grande distribuição, e mais ou menos importantes segundo o volume das transações), quanto uma pedagogia política. Este campo de experiências 
aparece, assim, marcado (segundo nossa leitura) por uma tensão entre lógicas distintas, que se traduz na realidade dessas iniciativas ao conflito, opondo certos imperativos funcionais (impostos pela necessidade de aumento das vendas dos produtos como consequiência da sua abertura sobre a grande distribuição) à necessidade de afirmação do sentido do projeto pela sua contribuição com a mudança das condições de injustiça da realidade do comércio mundial - numa perspectiva de conscientização do consumo.

\section{b) A finança solidária}

Neste universo, consideramos um conjunto de experiências também conhecidas sob outras expressões (microcrédito, poupança solidária, microfinança, finança de proximidade etc.) - que participam da construção de um outro tipo de relação com o dinheiro. O objetivo da finança solidária, dito de modo simplificado, é o de permitir que pessoas excluídas do sistema bancário criem seu próprio emprego. $\mathrm{O}$ desafio, portanto, deste campo de experiências, gira em torno da necessidade de democratização do acesso ao crédito, que vem fazer face ao problema da seletividade neste acesso e sua conseqüente limitação de oferta, ligadas à busca de rentabilidade das instituições financeiras.

Mas, para além de uma questão de democratização do acesso ao crédito, é, também (e sobretudo), toda uma preocupação com a chamada utilidade social do investimento financeiro que está em jogo, orientando este campo de iniciativas. Trata-se, assim, com estas experiências, de afirmação de uma finalidade de aplicação ética do dinheiro na direção daqueles projetos, articulando, por exemplo, um trabalho de luta contra a exclusão, de preservação ambiental, de ação cultural, de desenvolvimento local etc.

Os exemplos de iniciativas de finança solidária apresentam uma grande variedade. Citemos na França o caso dos CIGALEs (clubes de investidores para uma gestão alternativa e local da poupança), ${ }^{9}$ que se encontram articulados em rede. Estas associações mobilizam uma poupança de proximidade (a partir de seus membros associados) que é investida em projetos locais visando ao reforço do tecido econômico 
local e dos laços sociais. Trata-se de fomentar o desenvolvimento e criação de pequenas empresas da região. A prioridade do investimento é acordado, em geral, ao aspecto local e ao caráter de utilidade social da empresa, mas cada clube possui sua autonomia de decisão. Os CIGALEs funcionam então como uma espécie de sociedade de capital de risco solidário de proximidade. Além deste gênero de iniciativa (inúmeros outros exemplos poderiam ser considerados), este campo da finança solidária compreende ainda várias outras práticas, como o caso dos fundos de aplicação éticos ou solidários, já oferecidos mesmo por certos bancos tradicionais. Neste caso, o poupador renuncia a uma parte da remuneração da sua poupança ou aplicação em nome da utilidade social do investimento que é feito.

De experiências, na grande maioria dos casos, de pequeno porte, assiste-se hoje, neste campo da finança solidária, ao aparecimento cada vez maior de grandes instituições de crédito solidário. É o caso, por exemplo na França, da NEF (Nouvelle Economie Fraternelle), constituída enquanto banco em 1999, e da Caisse Solidaire de Roubaix desde 1996 - a primeira iniciativa neste país de uma sociedade financeira com vocação inteiramente solidária. Mas, a França não possui uma tradição de grandes bancos solidários, como existe na Alemanha, Suíça, Bélgica, Inglaterra ou Holanda. Neste último país, o exemplo da Triodos parece significativo: atuando em campos muito diversos, a Triodos tornou-se o principal investidor em parques eólicos no seu país. Este banco solidário financia, ainda, um quarto da alimentação biológica da Holanda.

Pela diversidade de experiências, este campo apresenta-se bastante heterogêneo quanto ao conteúdo das iniciativas, implicando o que consideramos aqui como um risco liberal. Ou seja, algumas experiências de finança solidária apresentam uma certa vulnerabilidade no sentido da possibilidade de sua apropriação sob a ótica de um discurso liberalizante do ponto de vista econômico. A concentração da ajuda sobre empreendedores individuais, como acontece em algumas experiências, ${ }^{10}$ pode conduzir a uma situação em que antigos assalariados transformam-se em novos terceiros sub-contratantes. Trata-se, aqui, de uma evolução instrumental, afetando a dinâmica das relações trabalhistas, que é acentuada pela moda do microcrédito junto às grandes instituições financeiras internacionais que defendem a multiplicação 
de microempresas independentes como alternativa positiva às regras protetoras da relação assalariada. A distinção, pois, da perspectiva da finança solidária em relação à abordagem liberal se situa sobre dois pontos: nestas experiências, de um lado, a seleção dos projetos a investir é fundado sobre critérios de utilidade social; e, do outro lado, uma ênfase é colocada sobre a importância do acompanhamento do projeto após seu início.

Observamos, assim, à imagem da própria dinâmica mais geral da economia solidária (tal como a definimos nas páginas precedentes), que o universo da finança solidária se posiciona numa imbricação entre três economias. Neste campo, tão diverso e complexo, certas experiências parecem mais próximas do setor bancário (mercantil), mantendo com ele relações de parceria privilegiadas para encontrar o essencial dos seus recursos; outras, assemelham-se mais a uma iniciativa pára-pública - tal é a intensidade da relação com o pólo não mercantil, em que os subsídios públicos são vitais para a sobrevivência da associação; outras experiências ainda parecem situadas numa posição mais equilibrada entre os três pólos (posição sempre difícil de manter), nutrindo o essencial dos seus recursos numa dinâmica reciprocitária.

Assim, a eficácia e vitalidade destas experiências se desenrolam numa relação de interdependência freqüentemente conflituosa, devido ao difícil exercício de uma parceria envolvendo diferentes lógicas de ação e mobilizando diversas formas de legitimidade. Para a maioria das experiências de finança solidária, o desafio se coloca em termos de sua autonomia e preservação do projeto inicial, em face das injunções do mercado e dos poderes públicos. Pois, tais iniciativas parecem, em grande parte dos casos, conscientes de certas derivas históricas dos setores mutualistas e cooperativistas (símbolos da economia social na França). Estes, tornaram-se na prática, isto é, do ponto de vista da sua dinâmica de funcionamento, imagem e cópia fiel de uma empresa convencional enquanto tipo organizacional, pois valoriza-se uma estrutura altamente tecnoburocrática de gestão.

\section{c) A economia sem dinheiro}

Tratam-se aqui de iniciativas participando da criação de formas alternativas de trocas ou intercâmbios econômicos, em relação àquelas 
praticadas segundo uma lógica de mercado. Tais iniciativas se situam numa escala local e buscam a articulação em redes como modo de organização territorial a fim de fazer face ao fenômeno da exclusão social.

Três tipos principais de experiências desenham este campo: a autoprodução coletiva; os sistemas de trocas locais chamados na França de systèmes d'échanges locaux (SEL), e mais conhecidos através das experiências anglo-saxônicas denominadas Local exchange trading system (LETS), mas, também conhecidos como tauschring na Alemanha, ou ainda, como redes de economia local (REL) na Itália -; e, as redes de trocas recíprocas de saberes, conhecidas na França como réseaux d'échanges reciproques de savoirs (RERS). Nestes dois últimos casos, os vários termos podem ser resumidos ao que se tem convencionado chamar na América Latina de clubes de troca.

Um SEL ou LETS consiste numa associação de pessoas (que atinge em certos casos centenas, e mesmo milhares, de associados) para trocar de outro modo (relativamente à forma mercantil) bens e serviços. $\mathrm{O}$ conjunto dos intercâmbios é contabilizado pela associação com o auxílio de uma moeda fictícia, e as dívidas são reguladas (mas jamais eliminadas) através de um sistema de compensação. A natureza das atividades ou bens trocados é bastante diversa: guarda de crianças, aulas (língua, cozinha...), serviços de reparo em geral (em marcenaria, encanamento, eletrônica...), produtos artesanais, objetos usados, serviços de jardinagem ou domésticos, empréstimo de ferramentas, etc.

A origem destas experiências remonta a 1976, na cidade de Vancouver, no Canadá. Rapidamente tais iniciativas se espalharam, principalmente em países como Estados Unidos, Inglaterra e Austrália. Esta origem está relacionada a contextos de crise econômica aguda (fechamento de fábricas, etc.), acompanhada pelo aparecimento de múltiplas experiências cooperativistas e comunitárias. Na França, o primeiro SEL foi criado em Lyon, em 1994. Estima-se hoje que há mais de mil experiências como essa no mundo.

Os SEL ou LETS não provêm de uma forma de troca mercantil, pois trata-se de um somatório de trocas (relações) bilaterais contabilizadas numa perspectiva de compensação multilateral, e não instantânea, das dívidas que devem durar no tempo. Vale ressaltar que o sentido mesmo do sistema é de fomentar uma dinâmica de dívidas e 
créditos a favor de uma perpetuação das relações sociais. ${ }^{11}$ Este mesmo impulso reciprocitário pode ser encontrado também nas experiências das redes de trocas recíprocas de saberes (RERS - réseaux d'échanges reciproques de savoirs). Todavia, diferentemente dos LETS, nestas iniciativas, a regulação das dívidas (também nunca eliminadas) se opera no quadro da própria bilateralidade da troca (sempre não instantânea), e não mais na multilateralidade das trocas relacionadas à totalidade associativa. Por outro lado, nestas experiências não se adota moeda local. Trata-se de trocas diretas de um saber contra um outro. Estas experiências, que visam igualmente a alimentar as relações sociais (o laço social), emergiram na França em meados da década de 70, para se estender em seguida a outros pontos da Europa. Contam hoje mais de 40.000 pessoas envolvidas.

Na visão de uma das fundadoras do RERS (C. Héber-Suffrin, 1998, citada por Laville, 1999), tais experiências têm um objetivo maior que é o de construção de uma cultura da reciprocidade. Esta última é definida como "uma tentativa de reequilibragem permanente", numa perspectiva de encontro coerente entre alteridade e igualdade: "ela é uma tensão permanente, construtiva e cognitiva". A singularidade destas experiências em relação a certas atividades ilegais, ou mesmo, a simples "viração" em família ou entre amigos, reside na sua inscrição no espaço público - exprimindo uma forma de solidariedade voluntária e um modo de relação igualitário entre os membros da associação.

Este campo da economia solidária apresenta, assim, uma característica fundamental em relação aos demais, referindo-se ao papel decisivo do pólo não monetário. Em grande parte dos casos, a expressão mais afirmada de uma lógica reciprocitária nestas experiências não parece significar sua assimilação a uma espécie de revivescência de formas antigas de solidariedade comunitária. Isto posto em razão do seu caráter democrático e da sua inscrição no espaço público.

Em função do deslocamento do pólo econômico dominante neste caso (do não mercantil para o não monetário), este campo esta sujeito a emergência de certos conflitos cuja natureza muda em relação à clássica confrontação Estado versus mundo associativo - que é particularmente marcante na França. 


\section{d) As empresas sociais}

Considerar a idéia de empresa social enquanto categoria tipológica, aqui, pode parecer redundante. Pois, de fato são, também, poderíamos assim chamar, empresas sociais que participam da finança solidária ou do comércio justo. Entretanto, pretendemos com este termo nos referir a um certo número de experiências de empreendedorismo social voltadas para atividades bastante variadas.

Mas, o que chamamos efetivamente de empresa social? Uma primeira compreensão deste termo sugere a idéia de organizações privadas desenvolvendo atividades comerciais, mas com finalidade social. Essa primeira aproximação do objeto nos parece um tanto quanto superficial, não nos permitindo ter acesso à natureza complexa deste fenômeno. De modo mais rigoroso, duas definições principais se sobressaem no inventário da literatura sobre este assunto, segundo Clément e Gardin (1999), apontando assim para duas abordagens distintas: a primeira é fruto das pesquisas realizadas pela OCDE, e a segunda origina-se nos trabalhos da rede EMES (Emergence of European Social Entreprises). ${ }^{12}$ Segundo a primeira definição.

"A empresa social faz referência a toda atividade privada de interesse geral, organizada a partir de uma démarche empresarial e não tendo como razão principal a maximização do lucro, mas a satisfação de certos objetivos econômicos e sociais, assim como a capacidade de dispor, pela produção de bens e serviços, de soluções inovadoras aos problemas de exclusão e de desemprego." 13

A segunda definição (pela qual nos sentimos mais próximos aqui) sublinha o caráter original deste tipo organizacional, considerado como posicionado numa encruzilhada de lógicas diversas. ${ }^{14}$ De um lado, se o poder não se funda sob a detenção do capital, em contraste no que se refere à lógica de uma empresa convencional, entretanto, ela desenvolve trocas comerciais. Do outro lado, se o seu grau de autonomia permite distingui-la de uma empresa pública, porém, ela se beneficia, na maioria dos casos, de subsídios dos poderes públicos. Inclinando-se sobre a organização socioeconômica dessas empresas sociais, a partir da idéia de interação entre diferentes registros do comportamento econômico, ou três pólos (mercantil, não mercantil e não monetário), estes trabalhos procuram afinar sua caracterização. Dois aspectos são sublinhados : 
- No que se refere à natureza das propriedade, uma multiplicidade de atores pode participar da estrutura de poder (assalariados, usuários, voluntários) e seus papéis apresentam um caráter difuso, aproximando-se, assim, do conceito de multiples stakeholders entreprises, ${ }^{15}$

- No que se refere aos objetivos organizacionais, a finalidade de uma empresa social é posta em termos de serviço à coletividade, "seja através de externalidades positivas que ela produz e/ou acesso igual de todos ao serviço que ela desenvolve" (Clément e Gardin, 1999). O que traduz o caráter de utilidade coletiva ou de utilidade social próprio deste tipo de iniciativa, justificando inclusive a natureza específica de sua propriedade (ou do seu poder), isto é, aberta à participação de atores organizacionais com estatutos múltiplos.

As empresas sociais em geral são objeto de um interesse particular da parte dos poderes públicos na Europa, que tendem a enxergar estas experiências como formas privilegiadas de potencialização de certas políticas sociais. Muitas delas realizam parcerias importantes com os poderes públicos. O grande desafio dessas iniciativas se coloca assim em termos de preservação do seu funcionamento democrático (que se encontra intimamente ligado ao grau de autonomia da experiência) face aos riscos de instrumentalização institucional. Ou seja, diante das injunções do Estado e do mercado, o desenvolvimento das empresas sociais coloca-as permanentemente em confrontação diante do risco de isomorfismo institucional. Isto é, a tendência ao rebatimento do modo associativo sobre um funcionamento de empresa privada ou de serviço público. Dito de outro modo, uma tendência à profissionalização da gestão das associações, em termos tecnoburocráticos, acompanha um certo nível de crescimento atingido, implicando a submissão da dimensão de projeto associativo (autônomo e espontâneo) aos imperativos funcionais (uma lógica instrumental), fundada sob um modo formal de gestão e a busca de resultados passíveis de quantificação.

O isomorfismo institucional é apenas uma conseqüência (em deriva), entre outras possíveis, da tensão dialética característica destas formas de organização atravessadas por lógicas diversas. Pois elas são, na maioria das vezes, ao mesmo tempo fundadas sob o registro de uma 
iniciativa cidadã (baseada em ideais de autonomia) e modelizadas no quadro de certas políticas públicas (experiências instrumentalizadas). A tensão será mais ou menos forte segundo o tipo de organização, assim como segundo o seu contexto de inserção, ou seja, as características do seu meio ambiente político.

\section{Cruzando o olhar... Que relação com o caso brasileiro ?}

Observa-se, assim, através desta diversidade de experiências, o projeto Europeu de uma economia solidária hoje desenhando-se num movimento multiforme de experiências. ${ }^{16}$ Seu ponto comum assinala a necessidade de recomposição das relações entre economia e sociedade, traduzindo, dessa forma, sua preocupação atual diante da tendência acelerada de mercantilização da sociedade, promovida por uma certa hegemonia do pensamento econômico neoliberal no plano político.

Todavia, em se tratando do caso brasileiro, estaríamos muito distantes desse tipo de prática européia? O que significa a idéia de economia solidária no nosso contexto de realidade? Parece-nos importante, em primeiro lugar, afirmar um certo caráter de universalidade do fenômeno. Isto implica reconhecer um número significativo de experiências por aqui muito semelhantes àquelas que acabamos de descrever, mesmo porque algumas redes de iniciativas de âmbito internacional já se elaboram, inclusive e sobretudo, entre os dois continentes - europeu e latino americano. ${ }^{17}$ Conhecemos no Brasil, e na própria América Latina, um número em franca expansão de experiências tanto dos clubes de troca quanto da finança solidária, através dos mais variados casos de bancos do povo e certas associações de microcrédito, além dos exemplos de empresas sociais muito relacionadas por aqui às formas autogestionárias de produção cooperativada.

Mas onde residiria, então, a singularidade brasileira de uma economia solidária ? Consideramos que ela reside no legado ainda forte de uma chamada economia popular. Isto significa dizer que nossa economia de mercado, assim como nossa economia não mercantil, ambas, convivem (de maneira endêmica, para muitos) com as mais variadas formas de produção e distribuição econômica, constituindo um amplo tecido da sociedade em que não se desvinculam atividades econômicas 
das relações sociais no seu sentido mais estrito. Este "mar" de atividades permeando os circuitos do Estado e do mercado, que celebra quotidianamente as incompletudes da nossa modernidade, é mais conhecido sob a expressão de setor informal. Tal setor repousa grande parte dos seus recursos nas redes de solidariedade ordinárias, tecidas no próprio quotidiano da vida das pessoas. Ele reúne, ao mesmo tempo, três diferentes manifestações dessa informalidade. A primeira, mais conhecida sob a expressão de economia informal, refere-se aos vários casos de empreendedorismo individual que pretende reproduzir as trocas mercantis numa dimensão não formalizada da relação contratual. Ela representa, de um certo modo, um simulacro da economia mercantil, buscando integrar-se a ela, mas convive com um grau muito elevado de precariedade em relação a esta última. A segunda forma de manifestação da informalidade na economia é mais conhecida sob a expressão de economia paralela ou ilícita. Ela está baseada em formas despóticas de solidariedade e refere-se às atividades consideradas de contravenção pública baseadas no crime, como atesta o exemplo da organização do tráfico de drogas. Trata-se de um tipo de economia capaz de movimentar uma quantidade bastante elevada de recursos financeiros, permitindo, inclusive, níveis de renda aos seus participantes extremamente superiores aos do mercado formal de trabalho, mas que funciona sob o registro da violência. Por último, é preciso sublinhar aquelas formas de produção e distribuição econômica fortemente ancoradas em relações de reciprocidade, o que constitui a economia popular. Trata-se aqui de um modo coletivo de organização de trabalho, compreendendo desde formas domésticas de produção até formas mais cooperativas e democráticas de organização e trabalho. Tal tipo de economia, que inscreve a solidariedade no centro da geração de atividades e, em muitos casos, é fortemente não monetarizada, é que garante a sobrevivência de largas parcelas da população em sociedades como a nossa. É esta economia popular que parece encontrar-se na base do desenvolvimento da idéia de economia solidária entre nós.

Mas em que repousariam, mais precisamente, as diferenças fundamentais dessa economia solidária brasileira e latino-americana em relação ao caso europeu? Consideramos que esta diferença fundamental reside no âmbito da institucionalização do fenômeno mais elevado no caso europeu. O que implica sublinhar, de um lado, o grau de estruturação maior das experiências de economia solidária na 
Europa, assim como, de outro lado, o maior desenvolvimento do seu marco legal. Isto se deve em grande parte ao seu nível de articulação com o Estado. Muitas dessas experiências desenvolvem formas específicas de parceria com os poderes públicos, o que garante reconhecimento institucional e apoio financeiro, fatores estes muito importantes para a questão da sustentabilidade dessas iniciativas. Além disso, em vários desses países verifica-se um avanço significativo do debate acerca da formulação de um quadro jurídico específico (um marco legal) que possa regular a ação dessas organizações ${ }^{18}$ no sentido de potencializar seu desenvolvimento e evitar as costumeiras ações jurídicas que elas sofrem - tantas vezes acusadas de praticarem concorrência desleal por se beneficiarem, em alguns casos, de certas vantagens fiscais, oriundas do reconhecimento do seu caráter de utilidade pública.

Já no caso brasileiro, grande parte das experiências de economia solidária e popular estão marcadas por um grau relativamente elevado de precariedade, acabando por representar, em várias situações, quase que uma alternativa provisória de sobrevivência econômica. Vale salientar que a noção de precariedade atribuída a muitos empreendimentos aqui diz respeito sobretudo à precariedade material, implicando as condições de trabalho e o nível de renda econômica auferido pelas pessoas participantes das iniciativas. Mas não apenas de experiências precárias vive essa economia solidária latino-americana. Muitos são os casos de iniciativas de cidadãos que optam por outros valores associados ao trabalho. Nestes casos, encontra-se na origem do projeto organizacional menos a questão da necessidade econômica das pessoas engajadas no projeto e mais sua opção voluntária. Isto implica reconhecer o caráter diverso desse campo de iniciativas no nosso contexto. Embora ele permaneça, em todo caso, pouco reconhecido institucionalmente - à parte algumas parcerias com os poderes públicos que já se verificam de modo esparso, isto é, muito em função de tendências e conjunturas políticas específicas a certos governos locais. Do mesmo modo, o debate sobre um marco legal para a economia solidária brasileira está muito longe de aparecer na agenda política nacional, diferentemente do que ocorre com a noção de terceiro setor que ganha cada vez mais espaço, entretanto, na esteira do debate americano que parece pouco afeito às peculiaridades locais dos demais países. 


\section{Algumas lições práticas e teóricas}

Esse cruzamento do olhar entre dois contextos distintos da realidade do fenômeno, nos permite, desde já, algumas conclusões importantes sobre sua dinâmica. Em primeiro lugar, parece-nos relevante reconhecer que o grau elevado de institucionalização do fenômeno, tão unanimemente desejado em "terras tupiniquins", não se apresenta sem dificuldades conforme atesta o caso europeu, e francês, em particular. Ou seja, o maior reconhecimento institucional e apoio a esses empreendimentos por parte dos poderes públicos, em muitas situações, implica sua instrumentalização, interferindo, desse modo, diretamente sobre o grau de autonomia da iniciativa, bem como, a própria viabilidade do seu projeto enquanto organização, que corre o risco de perder o sentido como ação pública cidadã. É importante frisar, portanto, e em segundo lugar, que são as características de autonomia, de criatividade e inventividade organizacional, que se enfraquecem em muitos desses casos, comprometendo, então, o próprio sentido de ser de tais iniciativas. As soluções originais para os problemas sociais geradas através das mais diversas formas de economia solidária devem ser apoiadas e preservadas enquanto formas inéditas de ação pública, a fim de estimular e fomentar a inventividade e criatividade da própria sociedade. Esta parece ser uma primeira lição prática importante que tiramos do nosso estudo.

Entretanto, do ponto de vista mais teórico-conceitual, parecenos oportuno, neste momento, interrogarmo-nos sobre a efetiva pertinência do arcabouço de idéias aqui apresentado em relação à compreensão da nossa realidade. Sem dúvida que uma concepção plural da economia, tal como fora particularmente aqui desenvolvida, parecenos extremamente fecunda para refletir sobre a realidade do nosso contexto econômico. Ela permite, ao mesmo tempo, a identificação e reconhecimento, bem como a possibilidade de uma compreensão mais aprofundada (abrindo uma perspectiva qualitativa de pesquisa) acerca do que se passa fora dos circuitos do mercado e do Estado, e que se revela tão representativo e significativo do que seja nossa dinâmica societária.

Na prática, portanto, a hibridação de princípios econômicos que se realiza através destas experiências aponta caminhos fecundos do ponto 
de vista de uma ação organizacional produtiva, cujo horizonte possa ultrapassar objetivos puramente econômicos. Múltiplas possibilidades de parceria entre agentes da sociedade e poderes públicos nos aparecem possíveis através deste fenômeno, sempre atento à perspectiva de preservação da autonomia dos projetos.

Reside justamente neste último aspecto, nos parece, o grande desafio de tais empreendimentos. Mobilizando diferentes legitimidades no plano da prática associativa, dado o seu nível de interatividade com o ambiente institucional, e operando distintas lógicas de ação (técnica, social, política, cultural, estética...) na condução da dinâmica organizacional, tais iniciativas encontram sua sobrevivência num nível de tensão entre racionalidades bastante elevado. Trata-se, portanto, de um equilíbrio, neste jogo de tensão entre lógicas, necessariamente incerto e de difícil manutenção no interior de sociedades cujos marcos regulatórios principais tendem a impor o seu registro de lógica. Uma das questões principais, portanto, que se coloca como desafio ao fenômeno da economia solidária é aquela da identificação dos fatores que permitem seu êxito, isto é, sua condição de equilíbrio. Dito de outro modo, face aos obstáculos enfrentados, sobretudo de natureza institucional, a questão que se coloca é aquela de saber o que deve permitir um certo grau de perenização a tais iniciativas.

A perspectiva da economia solidária tal como apreendida através desta abordagem que adotamos aqui, deixa-nos alguns ensinamentos valiosos. Em primeiro lugar uma reflexão acerca do sentido do agir econômico, implicando um olhar ampliado sobre o ato de produzir e distribuir riqueza (o fazer econômico). Ao desconstruir-se o entendimento convencional (ou neoclássico) da noção de economia, que a reduz à idéia de mercado auto-regulado, é possível percebermos outras dimensões da vida econômica, como aquelas regidas pela solidariedade, que garante (vale lembrar mais uma vez), a vida de amplas parcelas das populações na maioria das sociedades conhecidas. Tal dimensão, tão vital na prática concreta das relações econômicas, parece, entretanto, esquecida na teoria econômica convencional. Em segundo lugar, tal forma de percepção permite, ainda, recolocar os termos do debate acerca do trabalho produtivo nas sociedades modernas, indagando-se sobre o sentido e o propósito de um crescimento que não beneficia o conjunto da humanidade. Acrescenta-se pois, aqui, um 
componente ético à idéia do agir produtivamente. E, sobretudo, tal projeto de uma economia solidária põe no centro do debate público a importância dos valores no plano da vida humana associada. Esta, nas suas mais diversas formas de organização e produção, aparece muito mais complexa do que supõe o olhar de um calculador utilitário de consequiências.

\section{Notas}

1 No prefácio a França e Dzimira (2000).

2 Em especial, La grande transformation: aux origines politiques et économiques de notre temps (Paris: Gallimard, 1983). Nesta obra notável do início da década de 50, Polanyi sustenta que a grande transformação que conhecem as economias ocidentais nos anos 30 reside na reimbricação da economia com o social, pela via da regulação da produção e da circulação de riquezas operada pelo Estado-Providência, hoje em crise. A "grande transformação" introduzida pela modernidade, quanto a ela, residindo muito mais no processo de autonomização do mercado em relação aos demais princípios do comportamento econômico, como a "administração doméstica", a "redistribuição" e a "reciprocidade". Esta ruptura produzida pela modernidade é acompanhada de um "desencantamento do mundo", de uma objetificação das relações sociais, ou ainda, de uma despersonalização das relações econômicas, que o fenômeno da economia solidária visa justamente a tornar mais humanas.

3 A problemática da economia solidária aparece amplamente articulada à realidade da chamada nova questão social nos principais países europeus, como é o caso da França, em especial. A esse respeito ver, entre outros, os trabalhos de J. Donzelot (1991, 1994), P. Rosanvallon (1995), além do nosso texto de tese (França, 2001).

4 Poderíamos assim propor a leitura do contexto atual de uma economia solidária em termos de crise do trabalho, ou melhor, em termos dos limites da chamada sociedade salarial, para retomar o diagnóstico sociológico de R. Castel (1995). Na leitura de muitos economistas, tal situação define-se em termos de crise do chamado equilíbrio fordista.

5 É o caso por exemplo de uma dinâmica associativa em que a atividade da organização beneficia os próprios moradores de um bairro que participam também como membros da associação. Consideramos aqui os exemplos, entre 
outros, das chamadas "creches parentais" (creches parentales), ou ainda, o das régies de quartier na França (França, 2000, 2001; Dzimira, 2000).

6 Na França, por exemplo, existe aproximadamente o equivalente à metade do produto nacional bruto, ou mesmo três quartos deste, que não é apreendido pois corresponde a formas de produção que não têm tradução monetária (Insel, 1993). Se mesmo em países ditos desenvolvidos os números impressionam, o que dizer então da realidade do chamado terceiro mundo? Faltam, entretanto, pesquisas a esse respeito. Merece registro, contudo, o fato de que grande parte desta economia doméstica ou economia dos cuidados é largamente praticado pelas mulheres.

7 Encontra-se aí uma das descobertas empíricas centrais de M. Mauss, em seu famoso Ensaio sobre a dádiva. Ou seja, aquela segundo a qual boa parte das sociedades humanas funcionou (como funciona em alguns casos ainda hoje) baseada num registro de trocas muito diferente daquele da racionalidade econômica moderna. Apoiando-se justamente no trabalho fundador de M. Mauss (Essai sur le don: forme et raison de l'échange dans les sociétés archaïques, publicado em 1923) e, em particular, no seu conceito de dádiva, uma via paradigmática fecunda tem se desenvolvido na França numa perspectiva de refundação de certos pressupostos dominantes nas ciências sociais. Ela concentra uma crítica importante sobre o legado economicista que se apoderou das ciências sociais. São os trabalhos do chamado movimento anti-utilitarista nas ciências sociais, amplamente publicados e debatidos pela Revue du MAUSS, coordenada por Alain Caillé. Para uma leitura brasileira sobre este assunto, consultar dois artigos publicados na Revista Brasileira de Ciências Sociais, v. 13, n. 38, out. 1998: "Introdução à dádiva", de J. T. Godbout, e "Nem holismo nem individualismo metodológico: Marcel Mauss e o paradigma da dádiva", de Alain Caillé. Uma síntese importante deste paradigma é apresentado em França e Dzimira (1999, 2000).

8 Na origem do comércio justo (aproximadamente no início da década de 70), encontra-se uma convergência entre ONGs de países do Sul (implicadas em iniciativas de organização popular) e associações ecológicas ou de defesa dos direitos humanos de países do Norte - tudo isto num contexto de queda dos preços das matérias-primas no comércio internacional.

9 Clubs d'Investisseurs pour une Gestion Alternative et Locale de l'Épargne.

10 É o caso na França da ADIE (Associação pelo Direito à Iniciativa Econômica), que financia micro-projetos individuais de criação de empresas por desempregados. A ADIE inspira-se amplamente no exemplo hoje considerado 
emblemático da Grameen Bank, em Bangladesh, (considerado como o primeiro banco para pobres do mundo) que apoia iniciativas de camponeses sem terra. Tentando responder a essa crítica, que situa a experiência da ADIE mais sob o registro de uma economia da inserção (a caráter assistencialista) do que propriamente uma economia solidária, M. Novak (fundadora desta experiência) considera que se trata de buscar uma terceira via entre o emprego clássico e a assistência: aquela do trabalho independente.

11 Esse é o registro próprio da chamada lógica da dádiva, tal como descrita por M. Mauss (1950). Para uma distinção mais rigorosa entre lógica da dádiva e lógica mercantil, ver França e Dzimira (1999, 2000).

12 Esta rede reúne pesquisadores de 15 países da Comunidade Européia numa perspectiva de definição das características sociais, econômicas e políticas destas organizações.

13 Definição apresentada em Clément e Gardin (1999). A partir de uma tal definição (bastante formalista), e de certas características funcionais decorrentes, a OCDE oferece uma ampla variedade de exemplos que podendo se inscrever neste conceito de empresa social: Empresas de inserção francesas, Empresas inserantes belgas ou finlandesas, Cooperativas sociais italianas, Cooperativas de trabalho associado espanholas, Empresas de comunidades locais alemãs (ex-Empresas alternativas), Empresas comunitárias irlandesas ou escocesas (Community Business), Empresas intermediarias britânicas (Intermediaite Labour Markets Organizations), Empresas de inserção portuguesas, Cooperativas de serviços sociais suecas, Empresas comunitárias austríacas, Empresas comerciais com finalidade social americanas (Community Based Business, Community Wealth Entreprises), Movimento comunitário quebequense, Grupos comunitários neo-zelandeses, Cooperativas mexicanas.

14 Em particular, as idéias desenvolvidas por J-L. Laville e M. Nyssens no documento de trabalho redigido a partir de reflexões transversais da rede EMES. (L'entreprise sociale, éléments pour un approche théorique. Paris: CRIDA, 1999).

15 A este respeito ver Borzaga e Mittone (1997) ou, ainda, Pestoff (1998). É importante assinalar o termo "stakeholders", em alusão às pessoas enquanto partícipes de um interesse comum, no lugar de "stockholders", ou seja, dos acionários (ou pessoas enquanto acionárias). Este conceito (stakeholders) é particularmente importante, pois enfatiza a dimensão democrática do funcionamento da empresa, assim como, a idéia de utilização do lucro gerado 
com a finalidade de realização de objetivos sociais, ao invés de servir para remunerar o capital.

16 Embora multiforme, este movimento aparece cada vez mais articulado. $\mathrm{Na}$ França, por exemplo, várias redes associativas se afirmam como parte integrante do processo de construção e desenvolvimento de uma economia solidária, sendo inclusive signatárias de um "apelo em favor da abertura de um espaço para a economia solidária", publicado no jornal Le Monde de 18/06/97. Desde então, elas se reagruparam para constituir a Inter-Redes de Economia Solidária (IRES). Além de estruturado, este fenômeno conhece ainda um reconhecimento institucional crescente neste país, da parte do seu governo, cujo marco foi a criação da chamada Secretaria de Estado para a Economia Solidária, em março de 2000.

17 Dois encontros internacionais já foram realizados com o intuito de integrar experiências de economia solidária nos vários continentes. Foram os chamados simpósios internacionais de globalização da solidariedade, ocorridos respectivamente em Lima e no Quebéc, nos anos de 1997 e 2001. Dois atores-parceiros centrais dessa iniciativa, entre outros, foram a Rede Brasileira de Sócio-Economia Solidária e a Inter-Redes de Economia Solidária francesa.

18 Conforme atestam na França, por exemplo, as diversas consultas empreendidas pela Secretaria de Estado para a Economia Solidária durante os anos 2000 e 2001; assim como, o relatório de Alain Lipietz encomendado pelo Ministério do Emprego e da Solidariedade (já em 1999) sobre «a oportunidade de um novo tipo de sociedade com vocação social »; além da lei italiana de 08.11.1991, que regulamenta a noção de cooperativas sociais neste país. Isto posto apenas para refletir dois casos de países europeus.

Abstract. The present article discusses the solidary basic economy issue. It treats its origin as concept and it emergency context, placing it an European phenomenon. The text attempts to interpret this kind of practice under the economical anthropology perspective. This approach demonstrates great pertinence when suggesting a overcoming of the conventional economics, which allows the apprehension of certain dimensions of the phenomenon that would not be recognited in the neoclassical economical approach. The text still covers the different forms of manifestation of the solidary basic economy in the European context, stressing some of the main dilemmas and challenges faced in everyday 
practice of such experiences. The article ends with an exam of the Brazilian case concerning the phenomenon.

Résumé. Cet article discute le sujet de l'économie solidaire. On approche l'origine du concept et son contexte de déploiement sur le fond de la problematique européenne que le soutien. Le texte cherche à degager le sens d'un tel type de pratique, en s'appuyant sur une approche d'anthropologie economique. Cet approche semble assez fecond car il suppose une refondation de la définition conventionnel d'économie, ce qui permet la compréhension de certaines dimensions du phénomène mal perçue dans une vision économique standard. Le texte offre encore une description sur les différentes formes de manifestation de l'économie solidaire dans la realité européenne cherchant à souligner les défis pratiques de ces expériences au quotidien. Le texte se conclut avec une réflexion sur le cas brésilien de manifestation du phénomène en présentant les premiers esquisses d'une perspective comparative internationale sur le sujet.

\section{Referências bibliográficas}

BORZAGA, C.; MITTONE, L. The multistakeholders versus the non profit organization. 1997. (University of Trento, draft paper n.7).

CAILLE, A. Critique de la raison utilitaire. Paris : La Découverte, 1989.

. Don, intérêt et désintéressement: Bourdieu, Mauss, Platon et quelques autres. Paris : La Découverte, 1994. (Série Bibliothèque du MAUSS).

CASTEL, R. Les métamorphoses de la question social: une chronique du salariat. Paris : Fayard, 1995.

CLEMENT, H.; GARDIN, L. L'entreprise social. Domont, France: Thierry Quinquenton, 1999. (Collection Les notes de l'Institut Karl Polanyi.).

DONZELOT, J.; ROMAN, J. (Org.). Face à l'exclusion: le modèle français. Paris : Esprit, 1991.

DONZELOT, J.; ESTEBE, P. L'Etat animateur: essai sur la politique de la ville. Paris : Esprit, 1994.

DZIMIRA, S. Entretiens dans une crèche parentale de la banlieue sud-est parisienne. La Revue du Gerfa (Groupe d'Etudes et de Recherches sur le Fait Associatif), Paris, v.1, n.1, 2000. 
EME, B.; LAVILLE, J-L. (Org.). Cohésion social et emploi. Paris : Desclée de Brouwer, 1994.

. Economie plurielle, économie solidaire : précisions et compléments. Revue du MAUSS, Paris, n. 7, 1996.

FRANÇA, G. C.; DZIMIRA, S. Economia solidária e dádiva. Organizações e Sociedade, Salvador, v. 6, n. 14, 1999.

. Don et économie solidaire: esquisse d'une théorie socio-économique de l'économie solidaire. Paris : La Découverte, 2000.

FRANÇA, G. C. Une régie de quartier dans la grande couronne de l'est parisien. Revue du Gerfa (Groupe d'Etudes et de Recherches sur le Fait Associatif), Paris, v. 1, n. 1, 2000.

. Sociétés en mutation et nouvelles formes de solidarité: le phénomène de l'économie solidaire en question: l'expérience des régies de quartier au carrefour de logiques diverses. Paris, 2001. These (Doctorat) Université Paris VII.

. Esclarecendo terminologias: as noções de terceiro setor, economia social, economia solidária e economia popular em perspectiva. Revista de Desenvolvimento Econômico, Salvador, v. 4, n. 7, jan. 2002.

GUERIN, H.; VALLAT, D. Les finances solidaires. Paris : Thierry Quinquenton éditeur, Domont, 1999. (Collection. Les notes de l'Institut Karl Polanyi).

HEBER-SUFFRIN, C. Le savoir, la reciprocité et le citoyen. Paris: Desclée de Brouwer, 1998.

INSEL, A. La part du don: esquisse d'évaluation. Revue du MAUSS, Paris, n. 1, 1993.

KRAYCHETTE, G.; LARA, F.; COSTA, B. (Org.). Economia dos setores populares: entre a realidade e a utopia. Petrópolis : Vozes, 2000.

LAVILLE, J-L. Les services de proximité en Europe. Paris : Syros, 1992.

. Economie et solidarité: esquisse d'une problématique. In: LAVILLE, J-L. (Org.). L'économie solidaire: une perspective internationale. Paris: Desclée de Brouwer, 1994.

. La Crise de la condition salariale: emploi, activité et nouvelle question sociale. In: LAVILLE, J-L. Le travail, quel avenir? Paris : Gallimard, 1997. 
LAVILLE, J-L. Une troisième voie pour le travail. Paris : Desclée de Brouwer, 1999.

MAUSS, M. Essai sur le don. Forme et raison de l'échange dans les sociétés archaïques. In: MAUSS, M. Sociologie et Anthropologie. Paris : PUF, 1950.

PESTOFF, V. A. Beyond the Market and State, social entreprises and civil democracy in a welfare society. Ashgate : Aldershot, 1998.

POLANYI, K. La grande transformation: aux origines politiques et économiques de notre temps. Paris : Gallimard, 1983.

ROSANVALLON, P. La nouvelle question sociale: repenser l'Etat-providence. Paris : Seuil, 1995.

SERVET, J. M. (Org.). Une économie sans argent: les Systèmes d'Echange Local. Paris : Seuil, 1999.

SERVET, J. M.; VALLAT, D. (Org.). Exclusion et liens financiers: Rapport du Centre Walras 1999-2000. Paris : Econômica, 1999.

SINGER, P.; SOUZA, A. R. (Org.). A economia solidária no Brasil. São Paulo: Contexto, 2000.

SIQUEIRA, C. A. (Org.). Geração de emprego e renda no Brasil. Rio de Janeiro: DP\&A, 1999.

TEDESCO, J. C.; CAMPOS, G. L. R. (Org.). Economia solidária e reestruturação produtiva. Passo Fundo (RS) : UPF, 2001. 